\title{
RISK MANAGEMENT IN CONSTRUCTION PROJECT MANAGEMENT
}

\author{
Martin Schieg \\ University of Applied Sciences Augsburg, Baumgartnerstrasse 16, 86161 Augsburg, Germany \\ E-mail: martin.schieg@cbp.de
}

Received 0610 2005; accepted 20012006

\begin{abstract}
By adopting risk management, savings potentials can be realized in construction projects. For this reason, for project managers as well as real estate developers, a consideration of the risk management process is worthwhile. The risk management process comprises 6 process steps, which will be discussed in greater detail below. The integration of a risk management system in construction projects must be oriented to the progress of the project and permeate all areas, functions and processes of the project. In this, particular importance is attached to the risks in the personnel area, for, particularly for enterprises providing highly qualified services, specialized employees are essential for market success.
\end{abstract}

Keywords: risk management process, error, possibility and influence analysis, risk portfolio, risk team analysis, risk identification, risk analysis, risk assessment, risk policy

\section{Introduction}

The economic situation and the expansion of the EU give rise to considerations of how to be able to offer the principal more efficient and more economic offers. This requires a consistent structuring of the enterprise and continuous risk management when carrying out construction projects.

Construction projects are exposed to risks at the time of their coming into existence. In the various stages, it must first of all be considered what risks the principal would like to counter with measures and how costly these measures are. For this, risks, possible risk costs, measures and costs of the measures must be identified and suitable measures must be found in order to avoid errors in the future.

The willingness of the real estate developers to take a risk that causes costs is common to all construction projects. The costs for risks are mostly not allowed for beforehand and thus reduce its profit margin. A consideration of the topic of risk management is worthwhile therefore and hence also the attempt to minimise costs due a failure to take precautions or avoid these completely.

Construction projects vary with the course of development, planning, realization and operating. Despite their uniqueness, recurrent processes of these phases can serve as a cornerstone for the recognition of risks in order to consider project-specific and known risks more closely. In this, particular importance is attached to the implementation and realization phase.

While in the past claims for damages were regularly presented subject to the precondition that an actual or rather obvious damage or loss at the structure had occurred, in the meantime the claim is increasingly asserted in the case of defects that have not (or not yet) led to damage or loss at structures. The claims for damages for resulting costs and other pecuniary prejudices incurred by the contractor are increasing, e.g. ineffective regulations regarding contractual penalties, errors in the collaboration in the award of the contract, errors in the checking of invoices.

Risk management in the architect's and engineer's 
office should thus establish itself an essential part of project management.

\section{Definition of risk}

In theory, risk is usually defined as a positive or negative deviation of a variable from its expected value. In general parlance, risk is understood only as a loss. The definition of risk in the meantime not least takes into account thechances.

In order to turn risks into chances, the business owner must first know his / her risk sufficiently well. Risk management constitutes a strategy to avoid losses and use available chances or rather chances potentially arising from risks. The strategy demands from the person taking action a precise "consideration" and "assessment" of the situation and the scenarios probably occurring in the future. On this basis, decisions are made in the hope of having eliminated all risks and used all chances. This means recognizing potential risks and circumventing a threat by averting, evading or reducing their negative effects.

\section{Risk management}

Risk management in construction projects is of great importance, as shown in Fig 1. Although at the start of a project, through the introduction of risk management, an increased expense is incurred, this is compensated for, in particular through the advantages of risk management. In the planning phase possible risks for the subsequent project success can be identified and reduced through their incorporation into the planning. This has in particular effects on the observance of set dates and deadlines and thus also on the maintenance of the project costs. For the principal, observance of its due date for putting into service an operating unit is of great importance.

The risk potential analysis of a project states to what extent project risks influence the risk situation of the enterprise. Risk potential should be estimated without a detailed consideration of the individual risks at as little expense as possible.

Depending on the assessment of the risk potential, the risk management process is set in motion.

Risk management comprises the integration of basic principles of risk policy, the establishment of a riskconsciousness as well as the organizational integration. It is an impetus for the risk management process and is responsible for the control of risks in full knowledge of the current risk situation [1]. Through risk management, transparency increases, many problems can be avoided from the outset through proactive action, the project can be prepared for unavoidable problems. Through this, the consequences can be mitigated, and the project manager retains the control over his / her project.

The risk management process comprises several steps, which will be explained hereinafter and are represented in Fig 2.

\subsection{Step 1 Identifying risks}

Risks that are not recognized also cannot be assessed and dealt with. However, a complete coverage of the risks is impossible.

The task of risk management is therefore to cover the essential risks as completely as possible. Risk identification must therefore be carried in a way that is

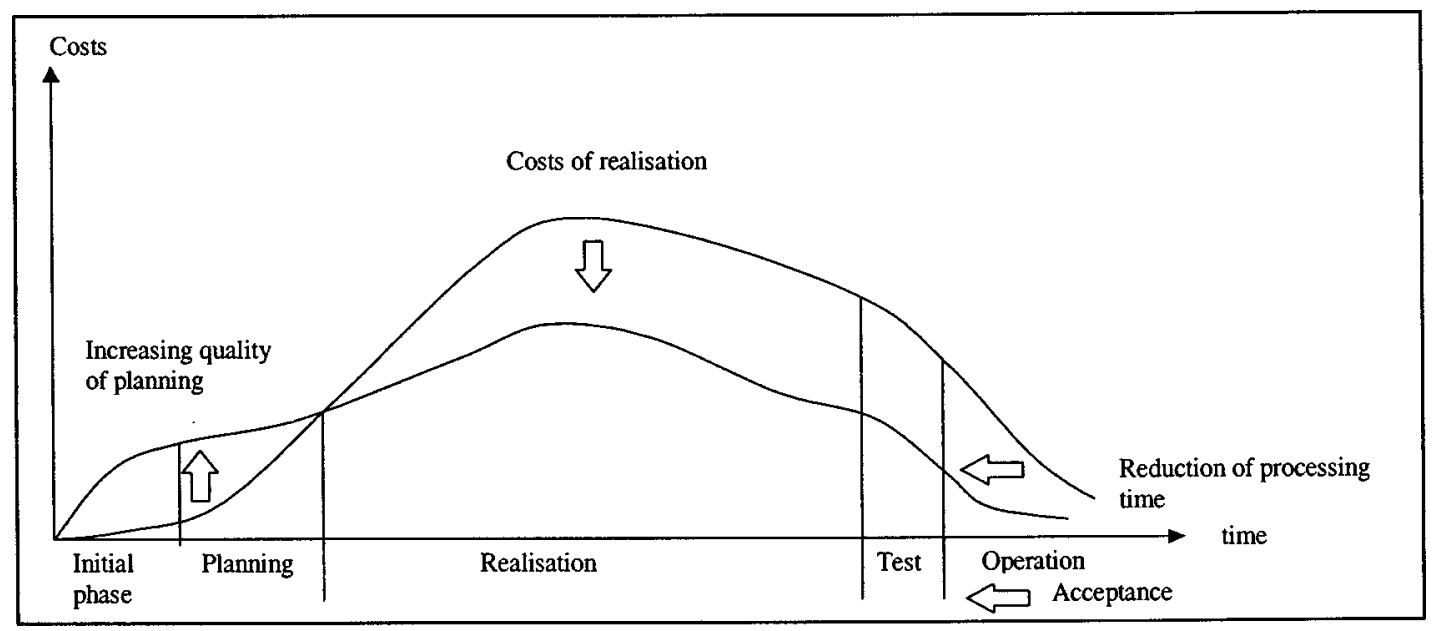

Fig 1. Potential through the use of risk management in construction projects 


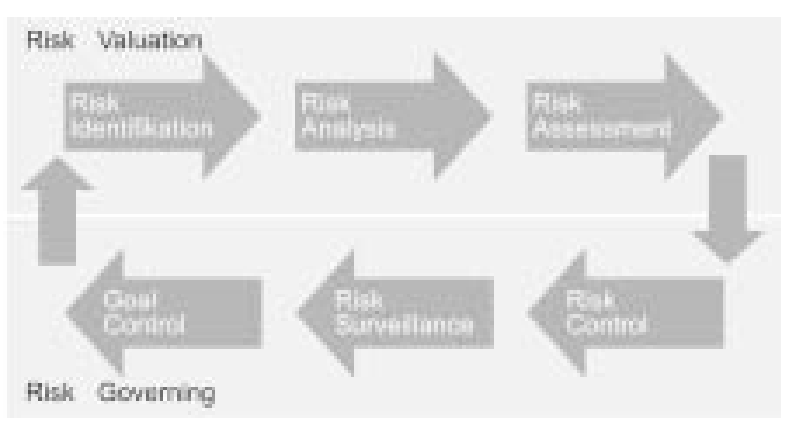

Fig 2. Elements of risk management

both forward-looking and in line with the progress of the project, since before the start of the project not all risks are completely recognizable and during the project implementation further risks may emerge. Fig 3 provides an overview of various methods for identifying risks. In principle, creative and guided methods are distinguished. The first type offers the possibility also to discover new kinds of risk. Guided methods use such as checklists for identifying risks, with the aid of which the conceivable types of risk are checked.

In projects, in particular the following risks occur, which are broken down according to risk types:

Quality risks

- Defect in interim results

- Lacking application of project methods

- Too few controls / tests

Personnel risks

- Lack of skills

- Disagreements in the team

Cost risks

- Planning changes

- Complicated project conditions

- Customer fails to pay

Set date / deadline risks

- No handover in good time

- The project end is delayed

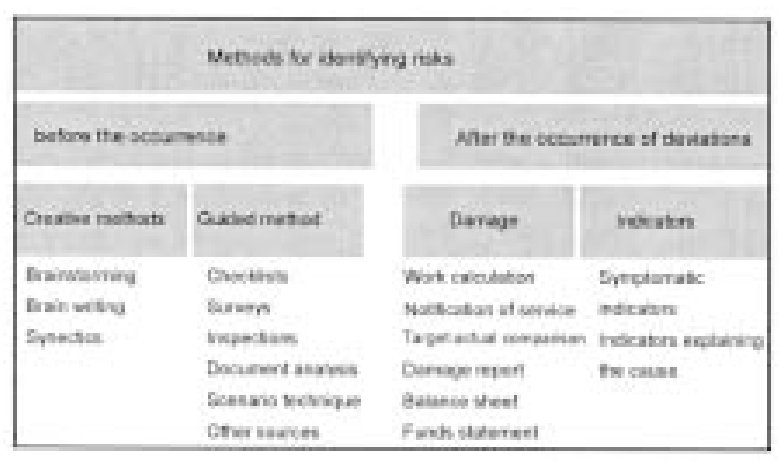

Fig 3. Methods of risk identification (according to Göcke, p. 143)
Risks of strategic decisions

- Failure to recognize chances

- Lack of ability to consistently use chances

External risks

- Natural occurrences

- Political changes

- Changes in society

- A shift in the market / new markets

- Legal developments

- Shifts in sectoral trends

- Technological changes

\subsection{Step 2 Analysing risks}

The objective is to describe the risk situation as completely and precisely as possible and to prioritize the risks. For this, the identified risks are investigated with regard to the probability of their occurrence and the effect on the project. In the first place, a portfolio and a risk costs assessment respectively serves for classification purposes. Criteria must be found, on the basis of which individual risks can be assessed and compared with one another.

A risk must always be described as a damage or lossentailing event to which a particular value can be allocated. From this, damage or loss assessed in terms of costs and the probability of occurrence, a value for the risk can be calculated [Fig 4].

Methods of risk assessment are e.g.:

$\mathrm{n} \quad$ Error, possibility and influence analysis

This is a largely formalized analytical method for the systematic coverage of all possible errors and for the estimation of the risks associated with these. In this, within a team, possible potential errors are determined with the aid of a standard error, possibility and influence analysis form, the consequences are investigated und the causes are established and assessed.

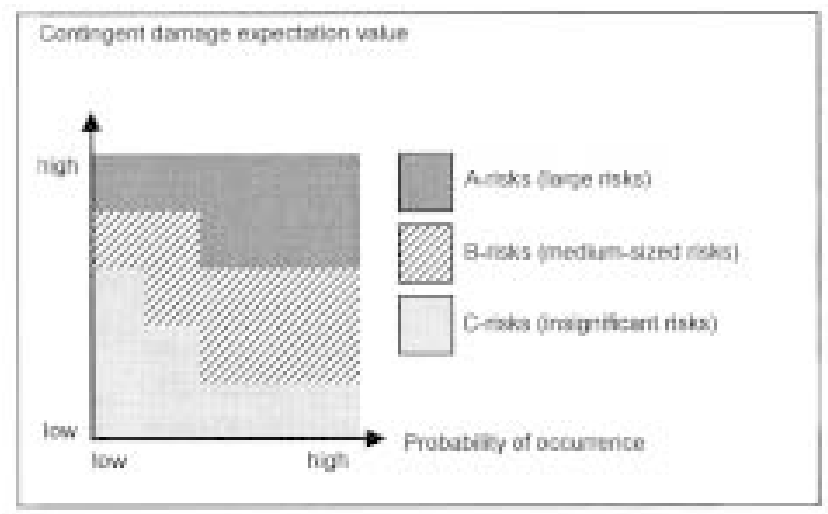

Fig 4. Risk classification 
Next, the causes of errors are systematically assessed in terms of the probability of their occurrence, the significance for the customer and the probability of their being discovered. Finally, suitable measures are commenced.

n The risk portfolio

In the risk portfolio risks are ordered according to the amount of damage or loss and the probability of their occurrence. Accordingly, the effects on the project and the need to take action are evaluated.

n Risk team analysis

The risk evaluation is carried out by the project manager in the context of project controlling. For the risk team analysis, risks are determined and analysed according to types and indicators for the occurrence of risk are worked out. From this, possible measures are elaborated and represented and persons responsible for the risk monitoring and notification are determined.

\subsection{Step 3 Assessing risks}

The risk assessment comprises the qualitative assessment and quantitative measurement of individual risks including the interrelationship of their effects. With the help of the results of risk assessment for example a risk portfolio of a project can be illustrated and compared with others.

While for the banking or insurance industry mathematically and statistically exact methods for risk assessment are useful, these cannot satisfy the typical risks in the construction industry. The following methods of risk assessment and risk comparison can also be used in construction projects:

n Key performance indicators

Key performance indicators cover quantitatively measurable circumstances and thus create a basis for comparison. They are preferably consulted for risk assessment if a large number of data and figures must be compared. For the key performance indicators, threshold values from which a risk warning exists are determined. Typical key performance indicators in the real estate sector are average operating costs, average rent, and vacancy rate or average interest on outside capital.

n Qualitative assessment

If no objective data is available, risks must still be quantifiable and made estimable. One method is qualitative estimation and weighting; in this, risks are assessed subjectively according to probability of their occurrence and the amount of damage or loss. n Probable maximum loss

The procedure of quantitative risk determination primarily aims at estimating the probabilities of dangerous occurrences within a risk scenario. In the evaluation of the risk of major damage or loss for example the maximum damage or loss possible or probable is determined.

n $\quad \mathrm{ABC}$ analysis

The $\mathrm{ABC}$ analysis is based on the recognition that frequently a relatively small number of factors make up the largest share of a whole. The goal of the analysis is therefore to find out what factors make up the largest part of the project value and in which therefore a greater planning and control expenditure is justified.

n Risk map

The risk map illustrates the risk profile of an enterprise. It is referred to as risk landscape, risk map or risk matrix [1]. In a risk map it can be read with what priority the risks should be approached. In this, the risks that cannot be borne, which could endanger the continued existence of the enterprise, are prioritized. The risk classification in a risk matrix thus enables a differentiated consideration of two classification criteria: probability of occurrence and expected value.

\subsection{Step 4 Controlling risks}

Controlling risk is the active influencing of the risks determined in the context of the risk analysis. Measures of dealing with risk can be differentiated between cause-related and effect-related measures. Cause-related measures are supposed to avoid or reduce risks, while effect-related measures serve to reduce or safeguard against the amount of damage or loss to be expected in the event of the damage or lossentailing event [3].

Strategies of controlling risk are accordingly the following:

- Avoidance

- Reduction

- Passing on the risk

- Bearing the risk by oneself

\subsection{Step $5 \quad$ Monitoring risks}

The monitoring of risks is the continuous operative control of the effectiveness of the risk control measures. The goal of risk management is not to eliminate risks completely from the project. The monitoring of the risk helps guarantee that the risk 
position of the project corresponds to the risk situation strived for.

This task is supported instrumentally through analyses of variances. The internal control system is part of the monitoring of the risk. The continuous monitoring of the early indicators and the repeated risk verification are carried out by the persons responsible in each case, no later than the respective milestone deadlines. A precondition for this is that a reporting and meeting structure in the organisation and for the project is stipulated. Besides the pursuit of the risk status and the progress of the measures, new additional risks must be included. Risks that have occurred must be documented with the relevant amount of damage or loss; critical situations of the managerial staff must be reported.

\subsection{Step 6 Controlling goals}

After the recognition, analysis and assessment of risks, measures for controlling goals must be taken. The control process may be broken down into sub-processes: determination of the target value, determination of the actual value, target/actual comparison and an analysis of variances. As a permanent process, in the context of the monitoring, the risk identification, analysis, and controlling are checked to find out whether the risk control is implemented in due form. In the event of variances between the actual risk situation and the risk situation strived for, steps must be commenced to specify the causes. Based on these recognitions, the risk strategy must then be adapted or revised. Consequently, by monitoring the risk it is guaranteed that standards set of risk management are taken into account.

\section{Risk management in the progress of the project}

Responsibility for carrying out the chance and risk management is borne by the project manager. The duty of the project management in the event of risk identification is to discover any emerging risks of a construction project and include these in a risk catalogue. For this, in practice, risk checklists that have been drawn up based on empirical values from comparable construction projects serve as ordinary auxiliary means. From the area of project controlling, in particular the following should be mentioned:

- Plan of services

- Pursuance of set dates / deadlines and progress

- Pursuance of costs

- Quality assurance

- Analysis of contracts
In order to encourage willingness to adopt risk management in the construction industry, standard risk checklists should be drawn up, with the help of which the project manager is only required to "tick off" the standard risks occurring. A quick instruction for project managers and teams that is easy to implement should result, which makes it possible to deal more easily with project risks.

The necessity to install a risk management system as early as possible results from the fact that risk potentials exist, at least in a rudimentary form, already before or at the start of the project and are recognizable, however their effects and damage only come to light in the subsequent progress of the project. For this reason, the risk management process should be established and integrated into the entire project process as a permanent (sub-) task of the project management. In this, the identification, analysis and assessment of risks must in each case be geared to the entire project and to special aspects of the individual project phases. In general, the progress of a project can be divided up into three phases:

- Start-up phase

- Manage phase

- Close phase

In this, typical risks occur in the corresponding phases. They must be integrated into the risk management process in order to prevent the progress of the project from being disturbed. For dealing with chances and risks in projects, the following principles apply:

- Responsibility for carrying out the chance and risk management is borne by the project manager.

- Only taking risks that one can influence oneself.

- Avoiding or safeguarding against risks that are influenced by others (customers, subcontractors).

- As far as possible, passing on risks taken.

- The consideration of chances und risks is a part of the project reporting

Below, with the aid of specific questions characteristic of the individual phases, it is shown where the tasks of risk management integrated into the progress of the project lie. Some questions are stated as examples, in which the type and scope of the questions can be expanded and supplemented at will. In this, the project breakdown carried out summarizes the project phases of the scope of services of project management [1], which was developed for project management by the AHO commission of experts in three phases. 


\subsection{Tasks of risk management}

\section{Start-up phase (project preparation; planning)}

The start-up phase corresponds to project steps 1 and 2 from the scope of services of the project control (section $204 \mathrm{AHO}^{2}$ ).

In the start-up phase the focus of risk management above all is on the check of the contractual and general circumstances of the project environment. The task of risk management is to recognize possible risks that can disturb the actual progress of the project. Here, risk management should investigate the following typical questions for identifying potential risks:

- Are the project goals clearly defined?

- Does clarity about the project structure exist?

- Have the future planners, advisers and consultants been selected and commissioned?

- Are there specific contractual features?

- Do gaps in services exist in the contracts?

- Is a concept of use available?

- Have the set dates / deadlines for the application for subsidies been complied with?

The scope of services of the project control comprises for certain partial services, such as e.g. the creation of a user needs programme, already comprises an analysis and assessment of the risks associated with this [2].

Manage phase (preparation of the implementation and implementation)

The task of risk management in the individual implementation phases of the project are characterized by the objective content of the project progress. In principle, during the project implementation, it is essentially a question of observing known risks from the start-up phase and their changes.

The effect of the measures taken to deal with risk must be assessed and additional risks must be analyzed regularly and in a results-oriented way.

For the manage phase, the following risk questions are characteristic:

- Are all resources available as planned?

- Does the principal comply with its duties to collaborate?

- Will the principal accept the entire project without serious defects?

Close phase (project completion)

The project end is reached upon the performance of the service and the handover (acceptance) of the structure to the principal (e.g. real estate developer). It becomes particularly critical if the principal refuses to accept the completed solution because the project result is not in accordance with its objectives. Risk management can help avoid such "failures" by pursuing the questions in the close phase:

- Were the contractual contents and undertakings fulfilled?

- Is a complete project documentation (records of meetings, correspondence, released project documentation etc.)?

- Is the contractually owed service "capable of being accepted"?

For the further development of the risk management system, it is important that stock is taken of the reflection on the progress of the project. In this, relevant questions are: What identified risks have occurred? What problems that have actually occurred in the progress of the project were not identified as risks and why not?

\subsection{Risks in the personnel sector}

Structural upheavals in the world of technology as well as dynamic changes in the sales markets can only be mastered successfully if the employees of an enterprise identify with this and are committed to this. Particularly for enterprises that offer highly qualified services, specialized employees acting on their own responsibility are essential for market success. For this reason, personnel risk management is necessary in order to not have to accept losses in tactical / operative competence and innovative potential through the departure of employees. Impressionable risk fields can above all be divided up into four areas: Bottleneck risk field, departure risk field, adaptation risk field and motivation risk field [3]; these will be explained briefly in the following section.

\section{Bottleneck risk field}

This is a matter of identifying in good time in what areas future top performers will be absent in the future. In this, the following questions stand in the foreground:

- What are the key qualifications for the future?

- Are strategically important staff positions safeguarded?

- How will the quantitative need for employees change in the future?

- How do the qualitative requirements made of the employees change due to new scopes of service or technologies?

Departure risk field

Departures of top performers generally constitute a high risk potential, in particular in long-term projects in 
which the project manager is the confidante of the real estate developer. Central reasons why employees leave an enterprise are: new challenges, more responsibility for decisions, better professional prospects with regard to career development, and good future perspectives of the new enterprise.

The following factors reduce the risk of departure and should therefore be taken into account by the business management: good business climate, favourable outline conditions for employee development, extensive non-material incentives on the part of the enterprise, remuneration structures adequate for the performance, suitable organizational structures and marked allocation of power potentials.

\section{Adaptation risk field}

Falsely qualified employees constitute adaptation risks. Should leaves of absence be avoided, as a precaution requalification or new qualifications are necessary. In construction projects here ongoing further training courses of the employees are necessary with regard to technological and legal changes. In construction project management changed scopes of service must be taken into account through a greater consolidation of services in the implementation of construction work.

\section{Motivation risk field}

Diffident services in many cases constitute a significant risk. Burnt-out employees or employees who have resigned in all but name are topical examples. The following behavioural risks are indicative of resignation in all but name:

- An absence of own initiative

- Overadapted behaviour

- Avoidance of conflicts

- An absence of constrictive criticism

- Undertaking less demanding work

- No longer exhaust existing competences

Possible instruments for reducing risks in the personnel sector are:

Promoting personnel development in a purposeful manner, coaching of managerial staff and employees, forcing identification with the enterprise through a corresponding corporate culture and creating motivation by granting more freedoms and self development.

\section{Conclusions}

Effective risk management must permeate all areas, functions and processes of the project. The goal therefore must be to negotiate risks, assess these or even make these marketable and reduce them emphatically. In this, a decisive factor in its success is in the end the interaction of all elements represented. A risk and control culture borne and experienced by all parties involved in the project has the effect of a connecting bracket that can safeguard the effectiveness of the structural and organizational measures of risk management. The key to this is the parties involved in risk management. Effective risk management requires commitment as well as the riskconscious behaviour of each individual. The motivation as well as the interplay of the parties involved in the project in the end determines the quality of the work and thus the success of the project.

Risk management successfully installed in the project offers the chance to gain a clear understanding of the goals, duties and contents of the service and the feasibility of the project. It provides an information basis for the quantitative data, sorted according to size, for the purpose of supporting decisions, such as e.g. the choice between costs and implementing goods or the comparison between several possible options. For this, however, it is necessary that a high quality of the status of information is always available in order to make determinations on the basis of useable and comprehensive information. Risk management can therefore only be implemented and enforced effectively if communication channels in the enterprise are created, which guarantee the direction of the information to the places concerned in each case.

Through the risk management used, the overall risk of the project is broken down into individual risks. For these, corresponding measures can be taken. Nonetheless, in each project residual risks remain. It remains a strategic decision whether these risks are taken and can be borne if they occur.

\section{References}

[1] Cf. Marc Diederichs. Risikomanagement und Risikocontrolling, Verlag Vahlen, 2004, p. 14.

[2] Cf. Romeike, Frank: Lexikon Risikomanagement, Wiley-VCH Verlag, 2004, p. 113.

[3] Cf. Göcke, Bettina: Risikomanagement für Angebotsund Auftragsrisiken von Bauprojekten, DVP Verlag, Wuppertal, 2002, p. 169.

[4] Cf. AHO Ausschuss der Verbände und Kammern der Ingenieure und Architekten für die Honorarordnung e.V.: Projektmanagement Leistungen in der Bau- und Immobilienwirtschaft, No. 9, Stand Januar 2004, Bundesanzeiger, p. 9.

[5] Cf. ibid, p. 34.

[6] Cf. Dr. Leidig, Guido: Risikomanagement im HumanRessourcen Bereich, Der Betriebswirt 1/2002, S. 28 et seq. 